LA-7255-MS

Informal Report

$8-3 \cdot 7^{8}$

46.319

UC.25

Issued: May 1978

\title{
Fabrication of an Alumina Torus for Thermonuclear Fusion Containment
}

\author{
Willard E. Hauth \\ Rodger D. Blake \\ James M. Dickinson \\ Heidi L. Rutz \\ Stephen D. Stoddard
}

\section{scientific laboratory \\ of the University of California}

IOS ALAMOS, NEW MEXICO 87545<smiles></smiles>

An Alfirmative Artion/Equal Opportunily Employer 
FABRICATION OF AN ALUMINA TORUS FOR

THERMONUCLEAR FUSION CONTAINMENT

by

Willard E. Hauth, Rodger D. Blake, James M. Dickinson, Heidi L. Rutz, and Stephen D. Stoddard

\begin{abstract}
A $235-\mathrm{cm}$-diam torus has been fabricated for plasma containment during thermonuclear fusion experiments. This $30-\mathrm{cm}$-diam torus consists of sixty $99.5 \%$-alumina segments, $80 \%$ of which are assembled by forming vacuum-tight ceramic-toceramic seals. Selection of sealing materials and techniques are discussed.
\end{abstract}

\title{
I. INTRODUCTION
}

In thermonuclear fusion a confined deuterium-tritium gas at high temperature generates energy as a result of nuclear fusion of the deuterium-tritium atoms. Control of this energy form, which is the same as that of the sun, could provide much of our energy in the future. One approach to controlled thermonuclear fusion being investigated at the Los Alamos Scientific Labcratory (LASL) is the Toroidal Reverse Field Pinch Experiments. ${ }^{1-2}$ These experiments study the containment of plasma, which is heated and compressed by means of a large toroidal current. Experiment temperatures have ranged as high as $10000000 \mathrm{~K}$. The ceramic container required to perform these CTR experiments (for estabiishing economic performance criteria) is a high-purity alumina torus. A $235-\mathrm{cm}-0 . d$. torus has been fabricated as a reduced-size scaled test system for materials and accessory equipment systems (see Fig. 1). This 30- cm-tube-diam 
torus is designed to be a vacuum-tight ( $10^{-8}$ torr), $99.5 \%$-alumina assembly that can operate in a cyclical mode at temperatures as high as $150^{\circ} \mathrm{C}$. Information gained during fabrication and testing of this $30-\mathrm{cm}$-tube torus will provide the basis for fabrication of the full-scale $Z T-40$ torus. The 40-cm-tube torus wili have 57 us sapphire windows and 18 pump-out and instrumentation ports, each of which will be sealed radially in the torus tube wall (see fig. 2). The total ceramic-to-ceramic seal length for the 2T-40 torus will exceed $245 \mathrm{~m}(805 \mathrm{ft})$.

\section{DISCUSSION}

The basic approach of fabricating of this very large alumina assembly has been ceramic-to-ceramic sealing of the $99.5 \%$ alumina torus segments, pump-out tubulations, and sapphire windows. The ability to form a ceramic-to-ceramic seal between shapes as lárge as $30-\mathrm{cm}$-diam tubes is not an established commercial technique, particularly for the available sealant materials. ${ }^{3}$ The need to minimize the problems resulting from the use of organic 0-rings and the ultimate complications of fabricating multiple ceramic-toceramic seals, dictated the use of several inorganic sealant materials. Ideally these materials should be compatible, both physically and chemically, and should provide different maturing conditions covering a wide temperature range. The basic materials requirements for these ceramic-to-ceramic seals are:

(1) a close coefficient of thermal expansion match between the components and the sealant; (2) good sealing action when fired at 
relatively slow heating rates (that is, 20 to $50^{\circ} \mathrm{C} / \mathrm{h}$ ); and (3) the sealant forms a seal, and matures chemically, at temperatures significantly below the softening or slumping point of the components being sealed. The lack of known commercial sealants that can fulfill all of these requirements and provide adequate, yet controlled flow for these large seals resulted in a sealant development program at LASL. ${ }^{4}$

The initial phase of the torus assembly program consisted of evaluating chemical compatibility, determining wetting and flow properties, and measuring the coefficient of thermal expansion, for comnercially available materials and those developed at LASL. A prescribed quantity of sealant is applied to each of two $99.5 \%-$ alumina disks. These disks were fired using various temperatures and soak times. One disk was fired in a horizontal position; the other was fired at a $60^{\circ}$ angle to the horizontal plane. All tests were performed at a $25^{\circ} \mathrm{C} / \mathrm{h}$ heating and cooling rate to simulate the slow firing cycle required for assemblies of large torus segments. Materials designed to mature at temperatures exceeding $1300^{\circ} \mathrm{C}$ were not considered because of observed warpage of large 99.5\%-a Tumina ceramic assemblies when they are reheated above that temperature. The candidate materials had to flow and wet the disk in both firing attitudes without flowing off the disk. All but two of the comercial sealants were eliminated during this testing phase because of inadequate wetting and/or flow. Most of those eliminated were designed as minimum flow electronic package sealants, which macure 
at low temperatures (that is, below $1000^{\circ} \mathrm{C}$ ).

The two commercial sealants that performed satisfactorily are $X S-1175^{*}$ and $\mathrm{DC}-5 . \star \star$ Both are recrystallizing glasses designated as package sealants. Each is designed to be matured at 400 to $450^{\circ} \mathrm{C}$ in less than $15 \mathrm{~min}$ at temperature, with heating rates of 200 to $300^{\circ} \mathrm{C} / \mathrm{min}$. Test results in this development phase indicate that they perform satisfactorily when matured at $490^{\circ} \mathrm{C}$ and $525^{\circ} \mathrm{C}$, respectively, for soak periods up to $2 \mathrm{~h}$ and heating rates of 20 to $56^{\circ} \mathrm{C} / \mathrm{h}$.

Four sealants developed at $\operatorname{LASL}^{3}$ performed satisfactorily in the first development phase. These materials are designated compositions A-PBS-1, A-PBAS-5, A-BAB-1, and 1312 and are matured in the ranges 625 to $800^{\circ} \mathrm{C}, 800$ to $950^{\circ} \mathrm{C}, 950$ to $1100^{\circ} \mathrm{C}$, and 1200 to $1300^{\circ} \mathrm{C}$, respectively. They are soaked at temperature up to $3 \mathrm{~h}$ and are fired at heating rates of 20 to $50^{\circ} \mathrm{C} / \mathrm{h}$.

The second development phase for these six compositions included tests for chemical and physical compatibility and for optimization of joint designs and fabrication techniques for sealing tubes up to $40-\mathrm{cm}$ in diameter. Also, initial tests were ferformed to determine how well each composition sealed the sapphire windows and alumina pump-out tubulations. All of these sealants provide the following advantages:

* A product of Owens-Illinois, Inc. Toledo, $\mathrm{OH} 43666$. ** A product of Plessey, Inc. - EMD Division, Melville, NY 11746. 
- Each has been used to coat and seal ceramic components up to $20-\mathrm{cm}$ in diameter and to seal some $40-\mathrm{cm}$ diam alumina parts.

- Each can be applied by conventional spraying, brushing, dipping, and buttering techniques using water as the vehicle.

- Each, both raw and fritted, has been used to coat and seal after operations performed with one or more of the higher maturing temperature sealants.

- Each can repair seals and coatings fabricated from itself and any of the more refractory sealants.

- Each can be refired to its original maturing conditions with no apparent effect on seal vacuum and strength integrity.

This versatility permits the fabrication of large and/or complex ceramic assemblies in multiple stages and the modification or repair of seals and coatings previously formed in this manner. An example, shown in Fig. 3 , is a hermetically sealed assembly of eight 20-cm-diam 96\%-alumina cylinders. This assembly was fabricated in seven steps, using four different sealants. Some of the seals were refired as many as three times, in some cases, to their original maturing conditions.

The seals between segments for the $30-\mathrm{cm}$ torus are composition 1312. These assemblies (one is shown in Fig.4) will be joined with 0-ring seals to adjacent special diagnostic segments to form a torus. 
Each torus segment is a tube, $30-\mathrm{cm}$ in diameter, with a 6 -mm-thick wall, which forms $6^{\circ}$ of torus arc. Minimizing introduction of impurities into the plasma was a critical factor in developing a joint design for joining these tubes. The joint, as shown in Fig. 5, permits no line-of-sight contact between the plasma and the sealant and minimizes the area over which the seal must be fabricated to provide a vacuum-tight assembly. A joint of this design can also be sealed using an 0-ring. This use of 0 -ring seals is an obvious necessity, for a limited number of joints, to complete the assembly of a 235-cm-diam torus.

The special diagnostic segments to be fabricated for ZT-40 experiments include sealed sapphire windows and/or evacuation and instrumentation tubulation ports as shown in Fig. 2 . The 12 special segments include such designs as two segments with 17 sapphire windows in each, 6 segments with 3 port tubulations in each, and 2 segments with 2 ports and 9 windows in each. These complicated, sealed assemblies require multiple sealing steps as well as special fixturing to minimize movement and assembly distortion during sealing. After verifying that each candidate sealant can form satisfactory alumina to sapphire seajs, a program was undertaken to design a joining system that minimizes optical window distortion while facilitating fabrication with the windows in a vertical position. The ability to seal vertically aligned windows increases the possibility of fabricating multiple window seals simultaneously. The design that resulted from this work is 
shown in Fig. 6 . in this four component design a 99.5\%-alumina ring is inserted into the gap between the window and the alumiria seat after the sealant has been applied. This ring limits the flow of glass under the force of aravity during firing and prevents the movement of the sapphire window during processing. Also, this assembly system minimizes induced stress and alteration of flatness with the resulting phase distortion of light for the specially prepared sapphire windows. This optical quality in the sealed windows enhances analys is capabilities for fusion experiments.

The basic approach for fabricating the evacuation and instrumentation port seals is the same as that for the window seals. The small instrumentation ports are sealed in a seat using a glass-control ring. The larger evacuation ports will be sealed using a sealant reservoir at the interface of the torusport joint. A glass-control ring will also be used for fabrication of these seals.

\section{SUMMARY}

This work has established capabilities for fabricating a large, high-purity, complex alumina torus with alumina-to-alumina and alumina-to-sapphire seals, which will minimize the materials and container configuration problems in the ZT-40 Toroidal Reversed Field Pinch Experiments. In addition, this ceramic sealing technology is applicable to a wide variety of alumina fabrication problems and should be transiatable to several other ceramic systems. 


\section{Acknowledgments}

The authors wish to express their appreciation for support and advise provided during performance of this work by the following Los Alamos Scientific Laboratory CTR Division personnel:

Don A. Baker, Robert S. Dike, Joseph N. DiMarco, and Albert Haberstich.

\section{REFERENCES}

1. D. A. Baker and J. N. DiMarce, "The LASL Reversed Field Pinch Program PIan," Los Alamos Scientific Laboratory Report LA-6177-MS, (1975).

2. L. C. Burkhardt, "Toroidal Z-Pinch Demonstration," Los Alamos Scientific Laboratory Report LASL-77-3 Mini-Review, (1977).

3. W. E. Hauth and S. D. Stoddard, "State-of-the Art - Alumina Ceramics for Energy Applications," Bull. Am. Ceram. Soc. 57, [2] 181-185 (1978).

4. W. E. Hauth, "Ceramic-to-Ceramic Sealing," submitted for publication to the Am. Ceram. Soc. 


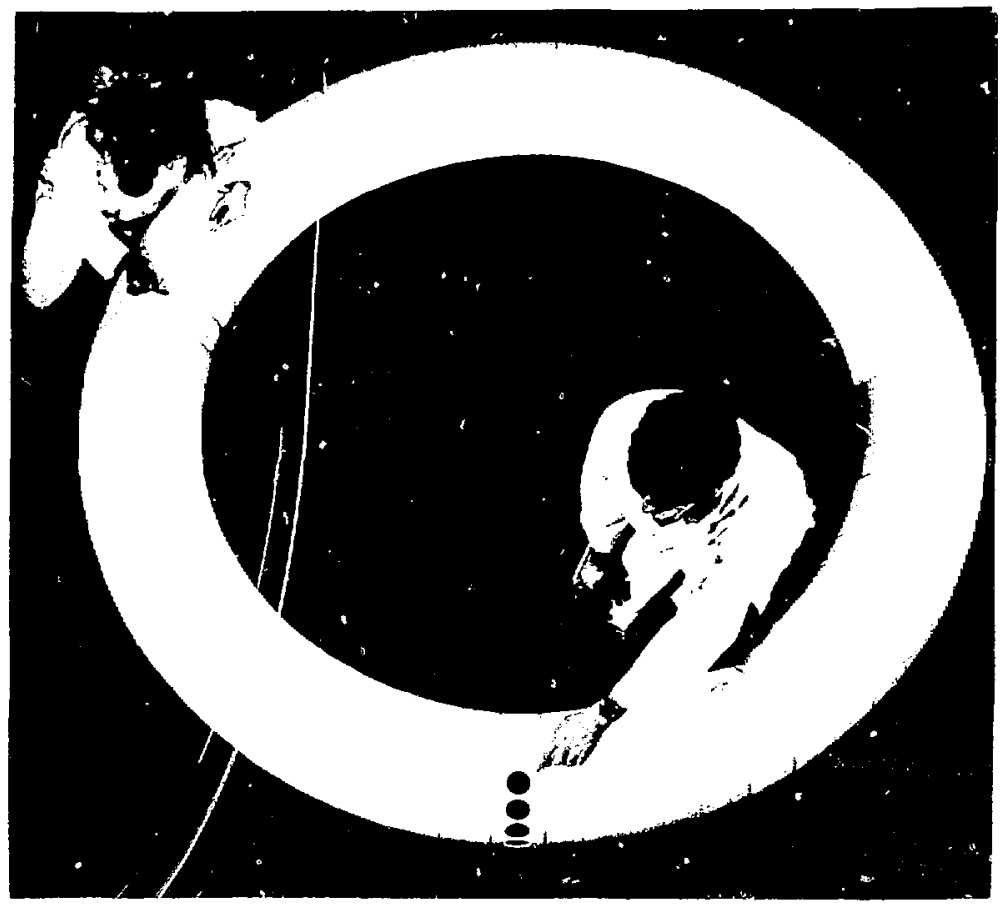

Fig. 1. Scaled-down version (30-cm tube diameter, 235-cm major diameter) of $40-\mathrm{cm}$ tube diameter ceramic torus for the $2 \mathrm{~T}-40$.

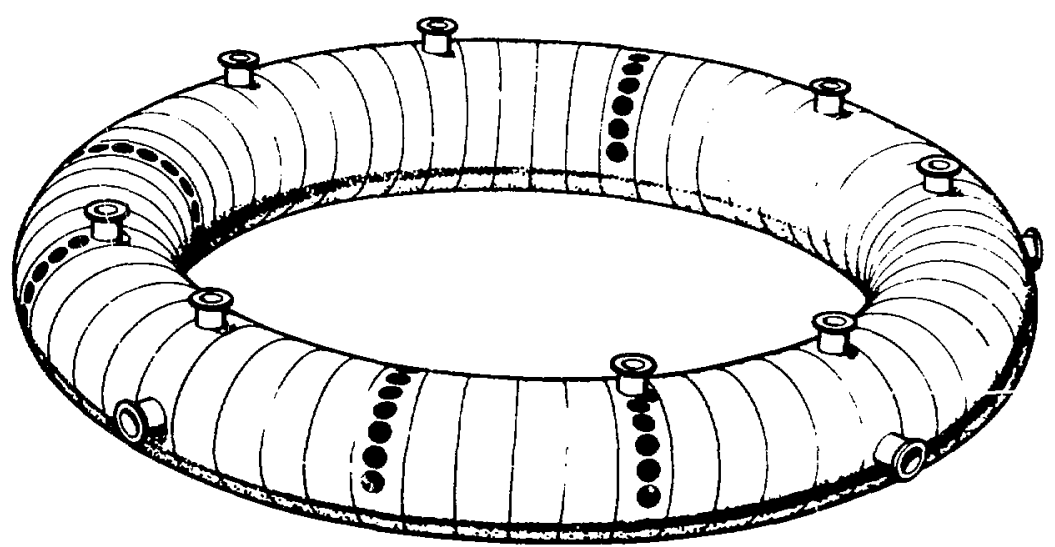

Fig. 2. ZT-40 torus showing sapphire windows and pump-out tubulations. 


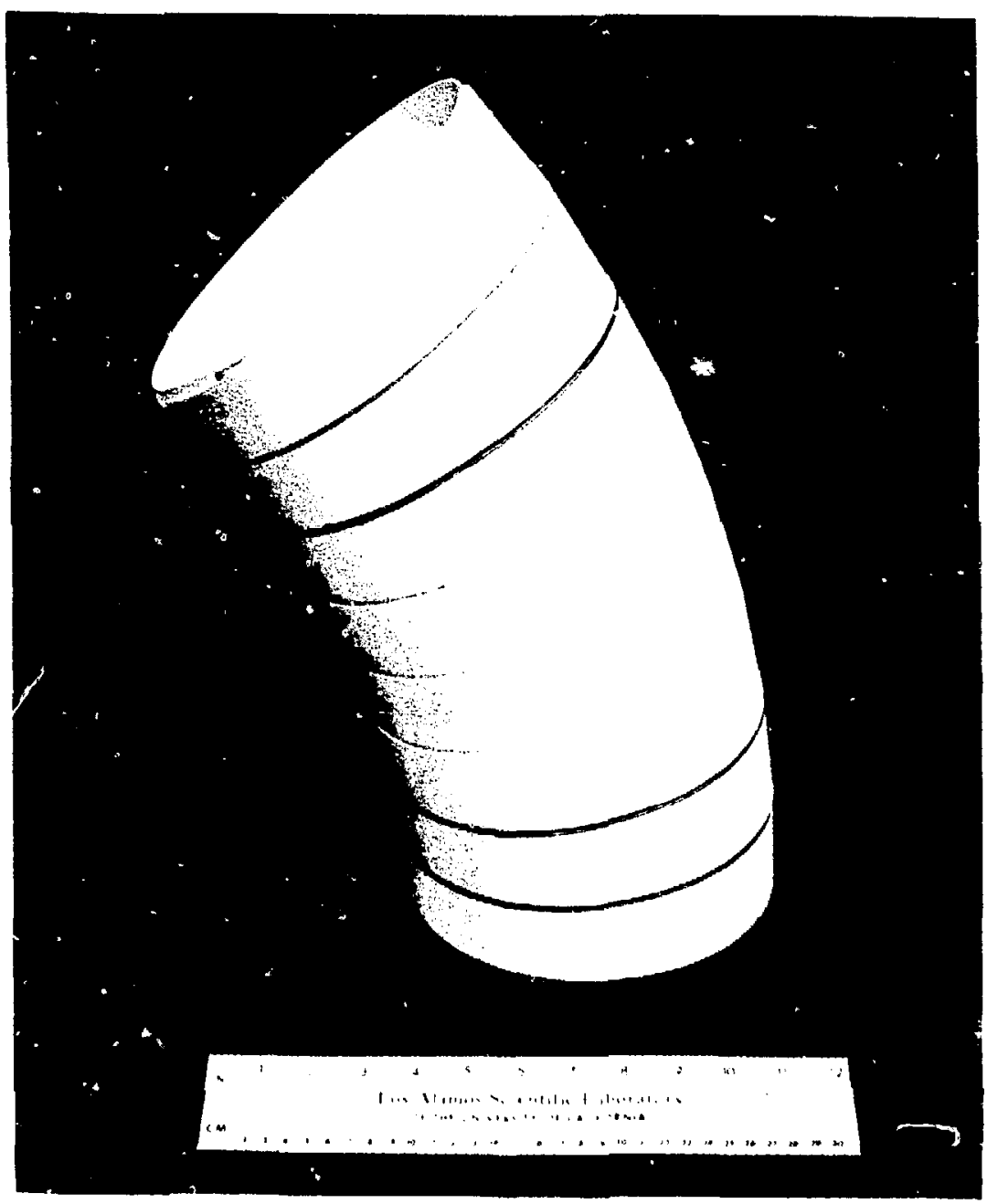

Fig. 3. Assembly of 2n-cm-diam 96.alumina tubes sealed with four sealants.

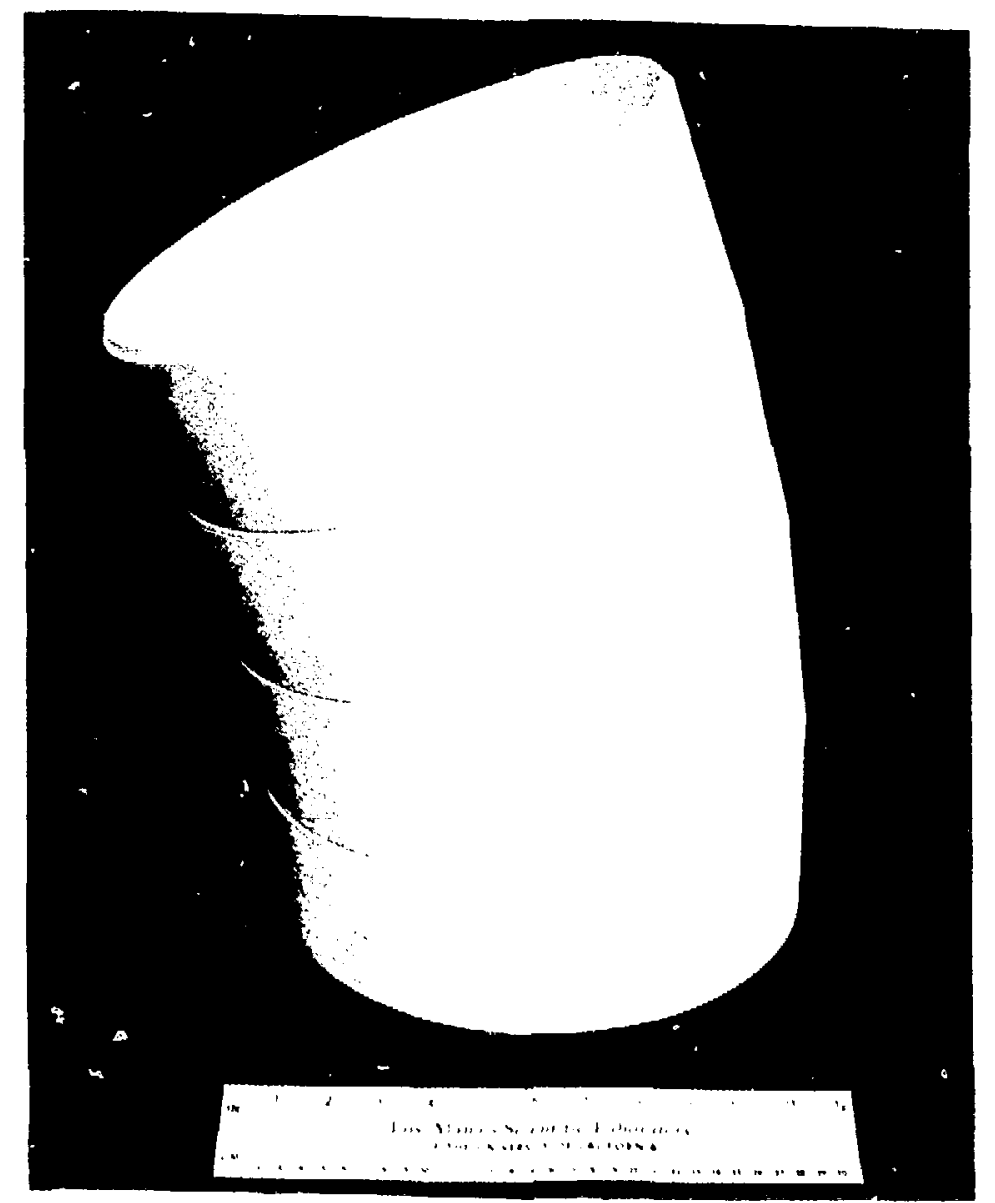

fic. 4. Sealed assembly of 3n-cm-diail 99.5 - alumina tubes. 

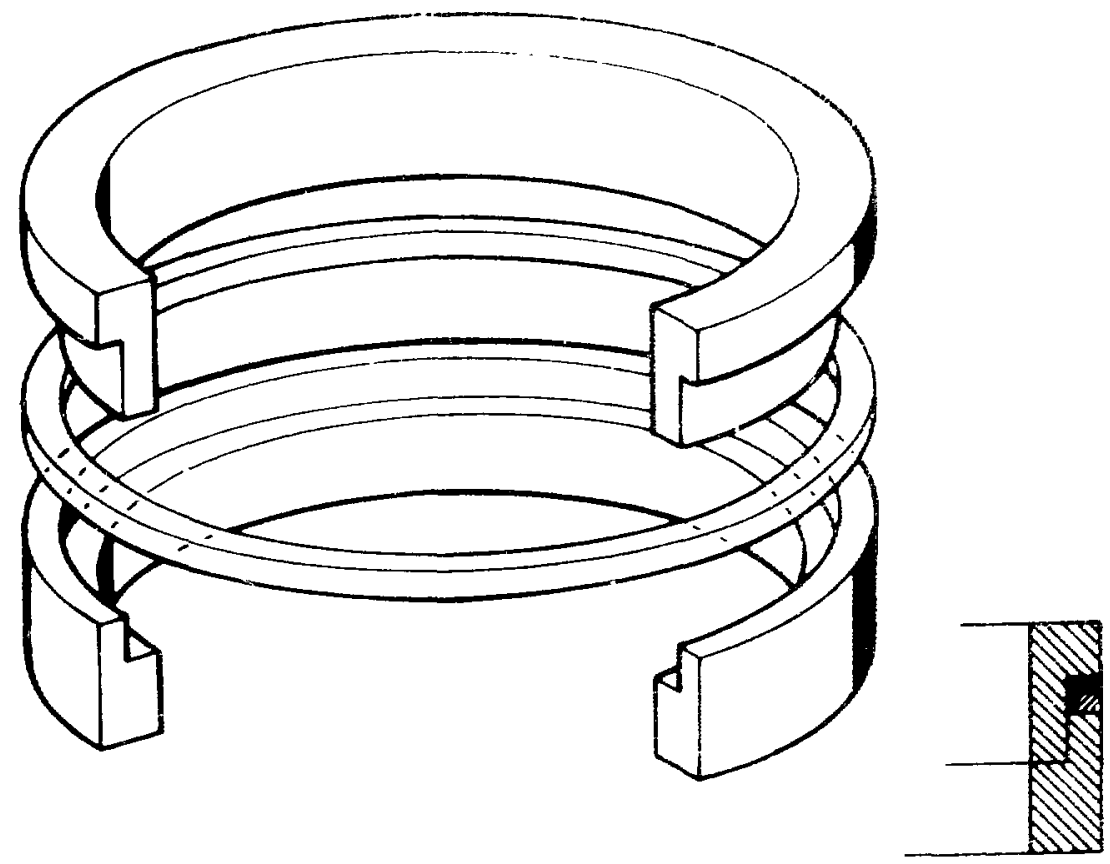

Fig. 5. Design for torus assembly int weals.

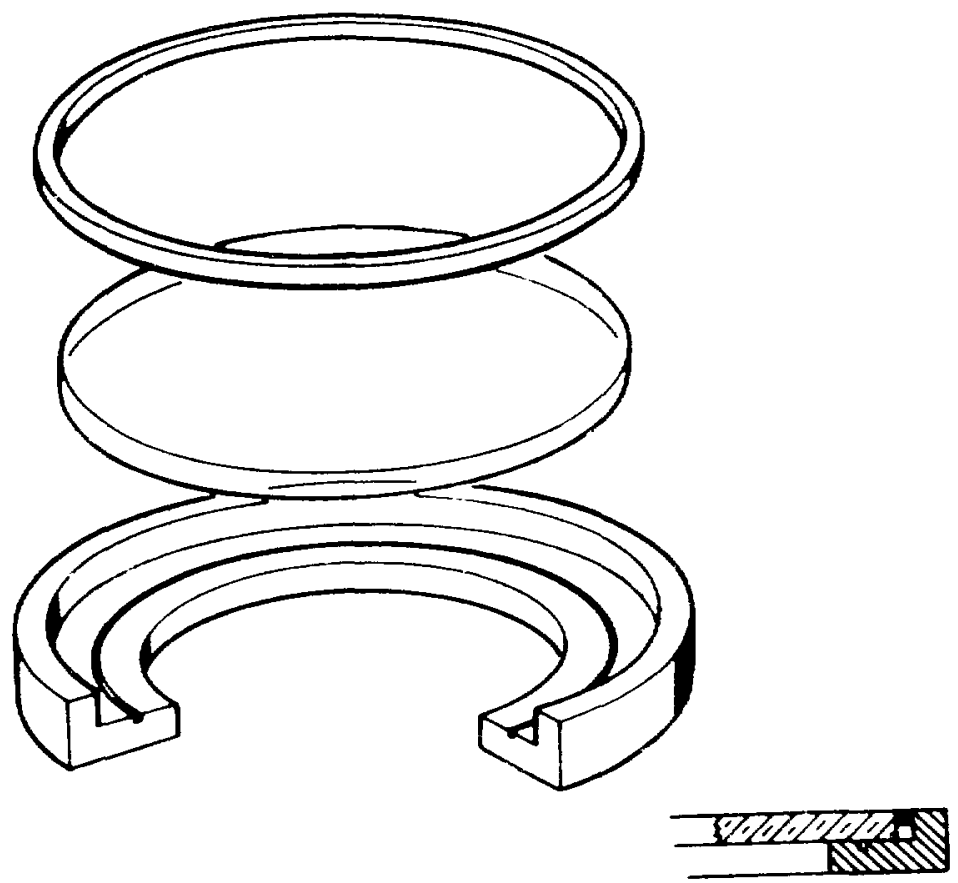

Fig. 6. Design for sapphire window seals. 